This is the final peer-reviewed accepted manuscript of:

Sassoni, E., Graziani, G., Franzoni, E., \& Scherer, G. (2017). Some Recent Findings On Marble Conservation By Aqueous Solutions Of Diammonium Hydrogen Phosphate. MRS Advances, 2(37-38), 2021-2026. doi:10.1557/adv.2017.45

DOI: https://doi.org/10.1557/adv.2017.45

The final published version is available online at: https://www.cambridge.org/core/journals/mrsadvances/article/div-classtitlesome-recent-findings-on-marble-conservation-by-aqueoussolutions-of-diammonium-hydrogen-phosphatediv/5E6C53E4FB91A74F53FF7DA18581D182

MRS Advances @ 2017 Materials Research Society

This manuscript version is made available under the Creative Commons AttributionNonCommercial-NoDerivs (CC BY-NC-ND) 4.0 International License (https://creativecommons.org/licenses/by-nc-nd/4.0/) 
Sassoni, E., Graziani, G., Franzoni, E., \& Scherer, G. (2017). Some Recent Findings On Marble Conservation By Aqueous Solutions of Diammonium Hydrogen Phosphate. MRS Advances, 2(37-38), 2021-2026. doi:10.1557/adv.2017.45

\title{
Some Recent Findings On Marble Conservation By Aqueous Solutions Of Diammonium Hydrogen Phosphate
}

\author{
Enrico Sassoni ${ }^{1}$, Gabriela Graziani ${ }^{1}$, Elisa Franzoni ${ }^{1}$ and George W. Scherer ${ }^{2}$ \\ ${ }^{1}$ Department of Civil, Chemical, Environmental and Materials Engineering (DICAM), \\ University of Bologna, Via Terracini 28, 40131, Bologna, Italy \\ ${ }^{2}$ Department of Civil and Environmental Engineering (CEE), \\ Princeton University, 69 Olden Street, 08542, Princeton (NJ), U.S.A.
}

\begin{abstract}
Given the lack of satisfying treatments for consolidating marble affected by thermally induced grain detachment (the so-called "sugaring"), the use of aqueous solutions of diammonium hydrogen phosphate (DAP) has recently been proposed. The idea is to form a new binding mineral (hydroxyapatite, HAP) as the reaction product between the DAP solution and the calcitic substrate. In this study, we investigated the effects of adding small quantities of ethanol (EtOH) to the DAP solution, with the aim of favoring HAP formation. The results of the study indicate that, when a $0.1 \mathrm{M}$ DAP and $0.1 \mathrm{mM} \mathrm{CaCl}_{2}$ solution in $10 \mathrm{vol} \% \mathrm{EtOH}$ is used, complete coverage of marble surface with a crack-free coating with reduced porosity is achieved (whereas no coating is formed without EtOH addition). This is thought to be a consequence of the weakening of hydration shells of phosphate ions in the DAP solution, thanks to the presence of ethanol molecules. When used to restore mechanical properties of weathered marble, the treatment with $10 \mathrm{vol} \% \mathrm{EtOH}$ was found to significantly improve the dynamic elastic modulus after a single application and to completely restore it after a second application.
\end{abstract}

\section{INTRODUCTION}

Marble has been used in architecture and sculpture since antiquity. Unfortunately, the anisotropic thermal behavior of calcite grains that constitute marble, together with its very low open porosity, make marble highly sensitive to temperature variations [1]. As a result of repeated thermal cycles, calcite grains lose cohesion and start to detach, leading to the so-called "sugaring" and making marble more susceptible to other decay causes (e.g., frost). Examples of sugaring marble elements in the New York Public Library (XIX cent.) are illustrated in Figure 1.

At the moment, no fully satisfying treatment for consolidation of sugaring marble exists, as organic treatments generally lack compatibility and durability with the substrate, while inorganic treatments generally have limited effectiveness. Recently, the use of aqueous solutions of diammonium hydrogen phosphate $\left(\left(\mathrm{NH}_{4}\right)_{2} \mathrm{HPO}_{4}, \mathrm{DAP}\right)$ for consolidation of sugaring marble has been proposed [2,3]. The idea, first proposed for limestone consolidation [4], is to form hydroxyapatite $\left(\mathrm{Ca}_{10}\left(\mathrm{PO}_{4}\right)_{6}(\mathrm{OH})_{2}, \mathrm{HAP}\right)$ as the reaction product between calcite grains and the aqueous DAP solution. Thus-formed HAP is expected to bind loose calcite grains and also protect marble the surface from corrosion in rain, thanks to the much lower solubility and slower dissolution of HAP, compared to calcite [5]. 

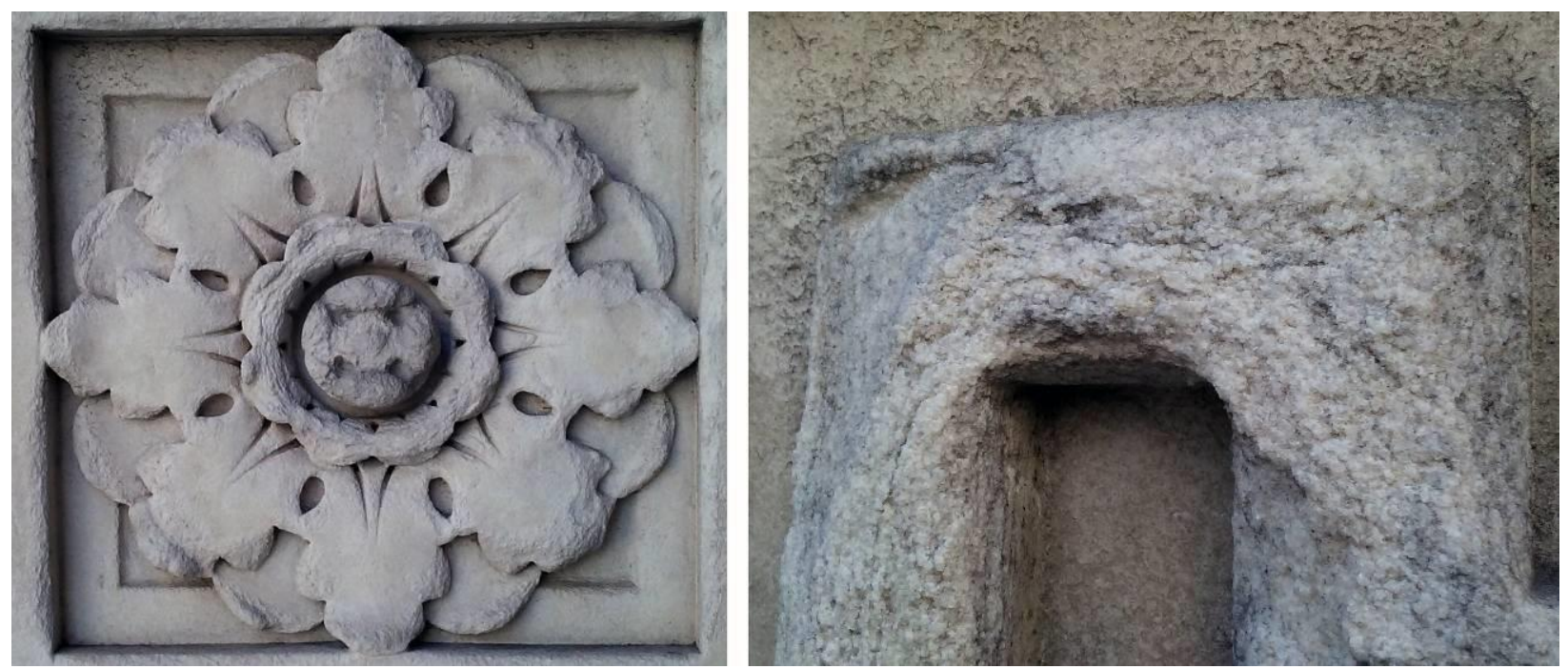

Figure 1. Examples of marble affected by sugaring in the New York Public Library (XIX cent).

In this paper, we report some recent results on the addition of small quantities of ethanol $(\mathrm{EtOH})$ to the DAP solution, to promote the formation of HAP. The present work was inspired by a previous study [6], where EtOH was found to favor the coverage of calcite grains with $\mathrm{HAP}$, also reducing cracking of the HAP coating.

\section{EXPERIMENTAL PART}

Carrara marble (provided by BasketweaveMosaics.com, USA) was used for the experiments. From a $1 \mathrm{~cm}$-thick slab, cubic samples with $1 \mathrm{~cm}$ side and prismatic samples with $5 \times 5 \times 1 \mathrm{~cm}^{3}$ size were sawn.

Cubic samples were used to test the effects of $\mathrm{EtOH}$ addition to the DAP solution on the morphology, cracking and porosity of the HAP coating. The same DAP and $\mathrm{CaCl}_{2}$ concentrations proposed in [6] were adopted (namely, $0.1 \mathrm{M} \mathrm{DAP}$ and $0.1 \mathrm{mM} \mathrm{CaCl}_{2}$ ) and different EtOH concentrations were tested (0.6, 6, 10 vol\%). In the case of $10 \mathrm{vol} \% \mathrm{EtOH}$ addition, double application was also investigated. In all cases, EtOH was added as the last component to the aqueous solution, already containing $0.1 \mathrm{mM} \mathrm{CaCl}_{2}$ and $0.1 \mathrm{M} \mathrm{DAP}$, because preliminary tests indicated this to be the addition order that favoured HAP formation the most. After treatment by immersion for 24 hours (the solution being continuously stirred), the treated samples were rinsed with deionized water and dried at room temperature. Then, the morphology of the new phases was analyzed using an environmental scanning electron microscope (FEI Quanta 200 FEG ESEM). To evaluate the porosity of the HAP film, the most promising samples (treated with $10 \mathrm{vol} \% \mathrm{EtOH}$ addition once and twice) were analyzed using a focused ion beam SEM (FEI StrataTM DB 235 FIB), that allowed cutting a cross section of the coating with minimal alteration.

Prismatic samples were used to test the efficacy of different DAP solutions to restore mechanical properties of marble preliminarily subjected to artificial weathering. This was performed according to a novel method we recently proposed to resemble marble weathering conditions in the field [7]. In brief, the method is to subject marble to high temperature by 
Sassoni, E., Graziani, G., Franzoni, E., \& Scherer, G. (2017). Some Recent Findings On Marble Conservation By Aqueous Solutions of Diammonium Hydrogen Phosphate. MRS Advances, 2(37-38), 2021-2026. doi:10.1557/adv.2017.45

putting it in contact with a hot plate for a certain time, the heating temperature and duration being determined by a mathematical model that takes into account the temperature-dependent thermal diffusivity of marble. The resulting samples are expected to exhibit more pronounced damage near the surface that was in contact with the hot plate, just as naturally weathered marble is more damaged near the external surface. In the present study, samples were heated on a hot plate already at $200{ }^{\circ} \mathrm{C}$ for 20 seconds (the sample's sides being insulated with a high temperature-resistant insulator), by putting a $5 \times 1 \mathrm{~cm}^{2}$ face in contact with the plate. The damaging effect was measured by determining the dynamic elastic modulus $\left(E_{d}\right)$ of the samples in the first $\mathrm{cm}$ near the hot plate and in the last $\mathrm{cm}$ (at 4 to $5 \mathrm{~cm}$ distance from the heated surface). $E_{d}$ was calculated from the ultrasonic pulse velocity (UPV), according to the formula $E_{d}$ $=U P V^{2} \times \rho$, where $\rho$ is the density. The $U P V$ was measured using a PUNDIT commercial instrument with $54 \mathrm{kHz}$ transducers. After artificial weathering, samples were treated with a 0.1 M DAP and $0.1 \mathrm{mM} \mathrm{CaCl}_{2}$ solution in $10 \mathrm{vol} \% \mathrm{EtOH}$, applied once and twice. Samples were vacuum impregnated and, after treatment for 24 hours, rinsed with deionized water and dried at room temperature. The increase in mechanical properties after consolidation was then assessed by measuring the $E_{d}$ as described above. The new phases formed after treatment were observed on fracture surfaces by ESEM.

\section{RESULTS AND DISCUSSION}

The addition of small quantities of EtOH was found to have a strong effect on the formation of the HAP coating. For the very low DAP and $\mathrm{CaCl}_{2}$ concentrations adopted in this study ( $0.1 \mathrm{M}$ and $0.1 \mathrm{mM}$, respectively), no coating was formed without $\mathrm{EtOH}$ addition (Figure 2,a). With the addition of $0.6 \mathrm{vol} \% \mathrm{EtOH}$, the coating started to form at grain boundaries between calcite grains. With increasing EtOH additions, the coating became progressively more continuous. With 10 vol\% EtOH addition, the marble surface was completely covered with the new HAP coating, that appeared to be crack-free (Figure 2,b). Such a strong effect of EtOH addition may be explained considering that, in the presence of $\mathrm{EtOH}$, the hydration shell of phosphate ions in the DAP solution is weakened and HAP formation is hence promoted [8].

The effect of EtOH addition was also confirmed by FIB/SEM analyses. The sample treated with 10 vol\% EtOH addition exhibited a quite dense microstructure (Figure 3, a), with much smaller pores than samples treated with higher DAP and $\mathrm{CaCl}_{2}$ concentrations $(1 \mathrm{M}$ and $0.1 \mathrm{M}$, respectively) but without EtOH addition (image not shown). Samples treated with double application of the treatment with $10 \mathrm{vol} \% \mathrm{EtOH}$ addition exhibited a further increase in density (Figure 3,b).

The variations in $E_{d}$ after artificial weathering and consolidation are reported in Table 1, which confirms the ability of the treatment to restore the cohesion and mechanical properties of weathered marble. After artificial weathering by contact with the hot plate, $E_{d}$ (originally equal to $72 \mathrm{GPa}$ ) decreased by $39 \%$ in the first $1 \mathrm{~cm}$ from the hot plate, while basically no damage was registered at a distance of 4 to $5 \mathrm{~cm}$ from the plate. These values are in fair agreement with what was predicted by the mathematical model, according to which an average $-35 \%$ decrease was expected in the first $\mathrm{cm}$, after contact with the hot plate at $200{ }^{\circ} \mathrm{C}$ for 20 seconds.

After consolidation with the DAP solution containing $10 \mathrm{vol} \% \mathrm{EtOH}$, a significant improvement in mechanical properties was registered (Table 1). In particular, in the most damaged part $E_{d}$ was increased up to $88 \%$ of the initial value with a single treatment. 

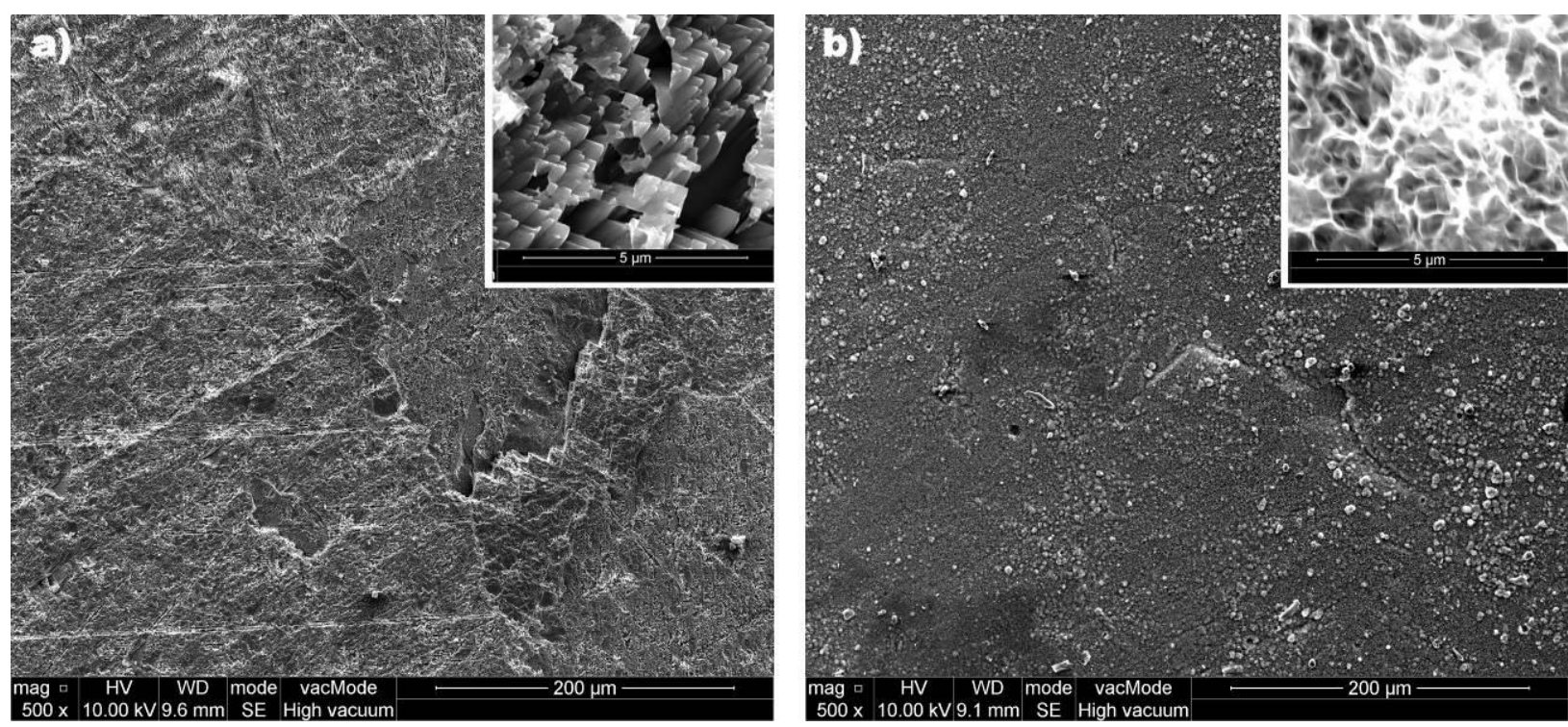

Figure 2. ESEM images of marble surface treated with $0.1 \mathrm{M}$ DAP and $0.1 \mathrm{mM} \mathrm{CaCl}_{2}$, without (a) and with (b) addition of 10 vol\% ethanol. Inserts reveal bare calcite in (a) and HAP in (b).
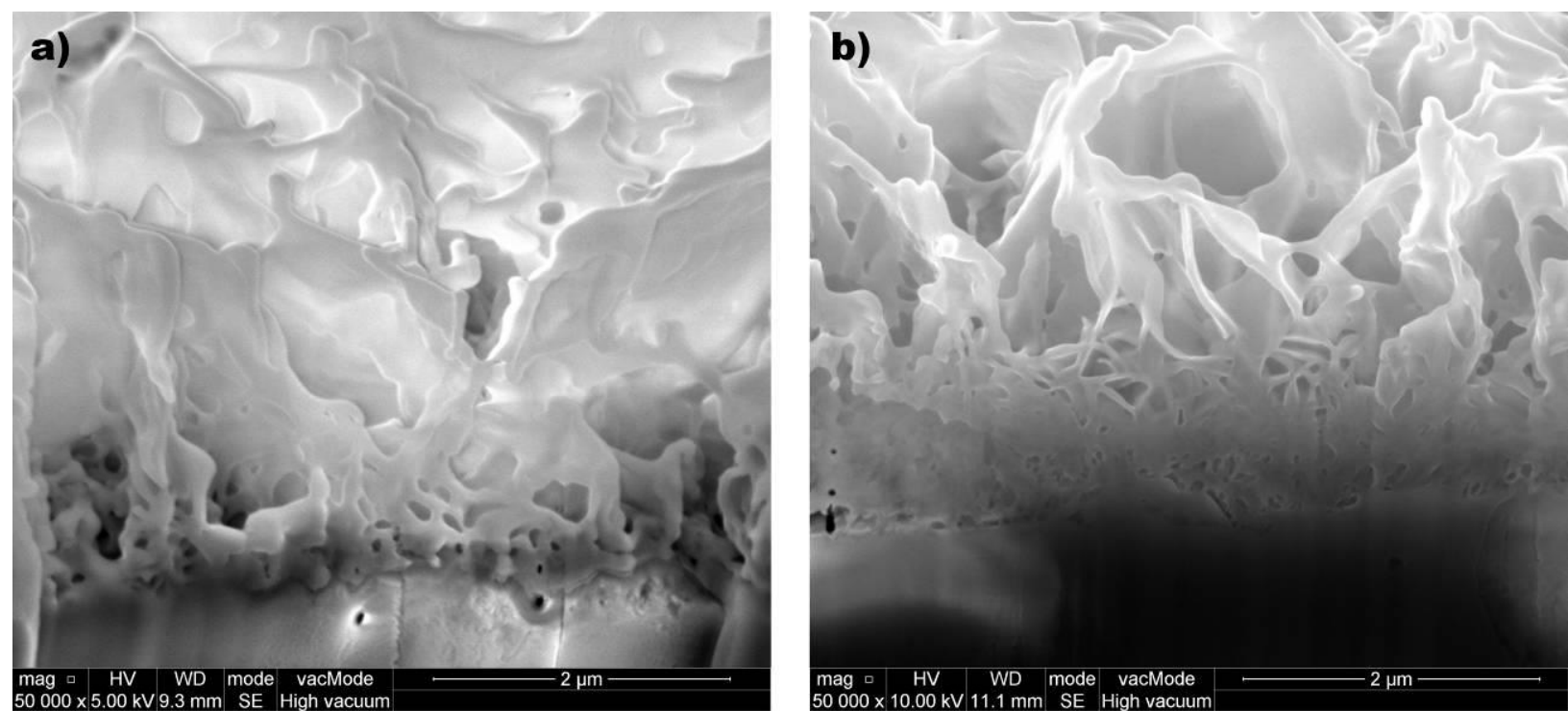

Figure 3. FIB-SEM images of cross sections of marble surface treated with $0.1 \mathrm{M}$ DAP and 0.1 $\mathrm{mM} \mathrm{CaCl} 2$ in 10 vol\% ethanol once (a) and twice (b).

This was made possible by HAP formation in the micro-cracks that had formed during artificial damaging, with a consequent healing action (Figure 4).

The original mechanical properties were completely restored by applying the treatment with $10 \mathrm{vol} \% \mathrm{EtOH}$ for a second time (Table 1). In this case, $E_{d}$ was increased up to $+13 \%$ in the originally damaged part; however, without causing excessive over-strengthening of the originally sound part (where $E_{d}$ increased up to $+16 \%$ ). 
Sassoni, E., Graziani, G., Franzoni, E., \& Scherer, G. (2017). Some Recent Findings On Marble Conservation By Aqueous Solutions of Diammonium Hydrogen Phosphate. MRS Advances, 2(37-38), 2021-2026. doi:10.1557/adv.2017.45

\begin{tabular}{|l|c|c|c|}
\hline \multirow{2}{*}{} & \multicolumn{3}{|c|}{$\%$ of initial $\mathrm{E}_{\mathrm{d}}$} \\
\cline { 2 - 4 } & $\begin{array}{c}\text { After } \\
\text { weathering }\end{array}$ & $\begin{array}{c}\text { After } \\
\text { treatment }\end{array}$ & $\begin{array}{c}\text { After double } \\
\text { treatment }\end{array}$ \\
\hline $1^{\text {st }} \mathrm{cm}$ (in contact with the hot plate) & $-38.9( \pm 0.3)$ & $-12.2( \pm 0.6)$ & +13.0 \\
\hline $5^{\text {th }} \mathrm{cm}$ (at 4 to $5 \mathrm{~cm}$ from the hot plate) & $-3.1( \pm 1.0)$ & $+3.3( \pm 1.2)$ & +16.0 \\
\hline
\end{tabular}

Table 1. Variations in dynamic elastic modulus $\left(E_{d}\right)$ after artificial weathering and treatment with $0.1 \mathrm{M} \mathrm{DAP}$ and $0.1 \mathrm{mM} \mathrm{CaCl}_{2}$ in 10 vol\% ethanol once and twice. Values after weathering and after the single treatment are averages for two samples (difference from the maximum/ minimum value in brackets), while a single sample was subjected to the double treatment.
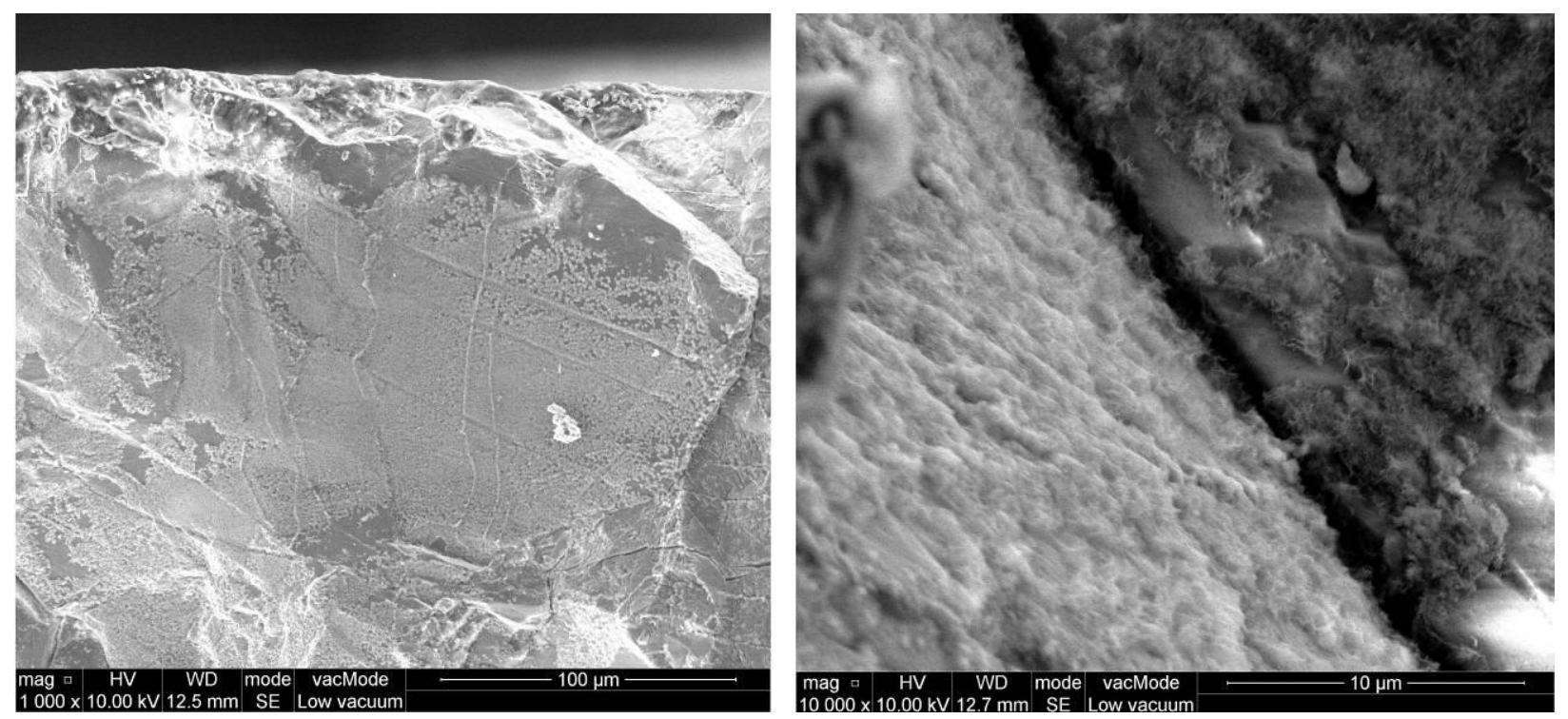

Figure 4. ESEM images of a fracture surface of marble preliminarily artificially weathered and then treated with $0.1 \mathrm{M}$ DAP and $0.1 \mathrm{mM} \mathrm{CaCl}_{2}$ in $10 \mathrm{vol} \%$ ethanol. The left image shows a white deposit of HAP that had formed in a grain boundary that was opened by artificial weathering; upon fracture, the treated boundary was exposed. The image on the right shows the texture of the HAP deposit on the boundary.

\section{CONCLUSIONS}

The addition of small quantities of ethanol to the aqueous solution of DAP was found to have a strong effect on the morphology, presence of cracks, and porosity of the new HAP coating formed on marble. Addition of $10 \mathrm{vol} \% \mathrm{EtOH}$ induced formation of a crack-free coating with reduced porosity. When applied to weathered marble, affected by the presence of micro-cracks, the DAP solution with 10 vol\% EtOH addition was able to cause a significant mechanical improvement after a single application and to completely restore the initial mechanical properties after a second application.

This qualifies this new formulation of the HAP treatment as one of the most promising for marble conservation. Further studies are currently in progress to test the protective action against dissolution in acidic water of HAP coatings formed with ethanol additions. 
Sassoni, E., Graziani, G., Franzoni, E., \& Scherer, G. (2017). Some Recent Findings On Marble Conservation By Aqueous Solutions of Diammonium Hydrogen Phosphate. MRS Advances, 2(37-38), 2021-2026. doi:10.1557/adv.2017.45

\section{ACKNOWLEDGMENTS}

This project has received funding from the European Union's Horizon 2020 research and innovation programme under the Marie Sklodowska-Curie grant agreement No 655239 (HAP4MARBLE project, "Multi-functionalization of hydroxyapatite for restoration and preventive conservation of marble artworks").

\section{REFERENCES}

1. S. Siegesmund, K. Ullemeyer, T. Weiss, E.K. Tschegg, Int. J. Earth Sci. 89, 170 (2000)

2. E. Sassoni, E. Franzoni, Appl. Phys. A-Mater. 117, 1893 (2014)

3. E. Sassoni, G. Graziani, E. Franzoni, Mater. Des. 88, 1145 (2015)

4. E. Sassoni, S. Naidu, G.W. Scherer, J. Cult. Herit. 12, 346 (2011)

5. S. Naidu, G.W. Scherer, J. Colloid. Interf. Sci. 435, 128 (2014)

6. G. Graziani, E. Sassoni, E. Franzoni, G.W. Scherer, Appl. Surf. Sci. 368, 241 (2016)

7. E. Sassoni, G. Graziani, E. Franzoni, G.W. Scherer, in Science and Art: A Future for Stone: Proc. of the 13th International Congress on the Deterioration and Conservation of Stone, edited by J. Hughes \& T. Howind (University of the West of Scotland, 2, 2016), p. 947

8. E. Lerner, R. Aoury, S. Sarig, J. Cryst. Growth. 97, 725 (1989) 